\title{
David Aven y otros v. Costa Rica: reflexiones sobre el interés (global) del medio ambiente en disputas de arbitraje de inversión
}

\author{
David Aven y Otros v. Costa Rica: Reflections on \\ the Environmental (Global) Interest in Investment \\ Arbitration Disputes
}

Tomás Restrepo Rodríguez*

Resumen: Este análisis aborda el caso de arbitraje de inversión internacional David Aven y Otros v. Costa Rica. Tras describir a manera de introducción los aspectos relevantes de la controversia, se resalta el problema jurídico que representa en esta decisión la tensión entre el deber del Estado Anfitrión de proteger los intereses del inversionista y el deber de proteger el interés (global) público del medio ambiente. Posteriormente, se evalúa la postura del Tribunal consistente en dar primacía al interés global público del medio ambiente a través de la predilección de la teoría de los poderes de policía y la aplicación del derecho internacional del medio ambiente; para rematar concluyendo que la decisión responde acertadamente al reclamo de la academia sobre la necesidad de rebalancear el equilibrio entre la protección a la inversión y la protección del medio ambiente.

Palabras clave: Derecho de inversión, arbitraje de inversión, medio ambiente, relajación regulatoria.

Docente-Investigador, Facultad de Derecho, Universidad Externado de Colombia, Bogotá, Colombia. Correo electrónico: tomas.restrepo@uexternado.edu.co 
Tomás Restrepo Rodríguez

\begin{abstract}
This analysis addresses the international investment arbitration case of David Aven y Otros v. Costa Rica. After describing as a way of introduction the most relevant aspects of the dispute, it is emphasized that the legal issue of the case embodies the tension between the Host State's duty to protect the invertor's interest against the duty to protect the (global) public interest of the environment. Subsequently, it is evaluated the position of the Tribunal that gives preference to the (global) public interest of the environment by means of adopting the police-power doctrine and the application of international environmental law; in order to conclude that the Decision answers to the call from the academia to re-balance the equilibrium between the protection to the investments and the protection to the environment.
\end{abstract}

Keywords: Investment Law, Investment Arbitration, Environment, Regulatory Chill.

\title{
1. La controversia
}

La disputa surge alrededor de un grupo de inversionistas estadounidenses que adquirieron los permisos y licencias necesarios para desarrollar un complejo turístico en la Costa del Pacífico Central de Costa Rica: el "Proyecto Las Olas" (David Aven y Otros v. Costa Rica, 2018, párr. 6, de ahora en más " $D A v$. CR"). Este proyecto - que ocupaba una porción de 37 hectáreas- fue suspendido por órdenes administrativas y judiciales cuando ya se encontraban en curso actividades de desarrollo, comercialización y venta (DA v. CR, 2018, párr. 6).

El motivo de la suspensión del "Proyecto Las Olas" fue el hallazgo de que la operación del complejo amenazaba humedales y terrenos forestales (DA v. CR, 2018, párr. 6). El demandante se opuso a la suspensión alegando que los estudios para otorgar la concesión del área y los permisos ambientales no contemplaron ab initio que los humedales y terrenos forestales se encontraran en riesgo. En este sentido, aquel alegó que la orden de suspender - a pesar de que el proyecto contaba con todos permisos nacionales y locales requeridos- era una medida "absoluta e imprevista" (DA v. CR, 2018, párr. 6) que causó la destrucción de la inversión (DA v. CR, 2018, párr. 6). 
David Aven y otros v. Costa Rica: reflexiones sobre el interés (global) del medio...

Concretamente, el demandante presentó reclamo en arbitraje internacional por considerar que la suspensión constituía violación de los artículos 10.5 y 10.7 del DR-CAFTA (Tratado de Libre Comercio entre Estados Unidos, Centroamérica y República Dominicana) que corresponden a los estándares de trato justo y equitativo y de expropiación, respectivamente ( $D A v$. $C R$, 2018, párr. 20). El monto de las pretensiones fue de aproximadamente 95.4 billones de dólares por daños y perjuicios ( $D A$ v. CR, 2018, párr. 184).

Por su parte, Costa Rica aseguró que el DR-CAFTA no solo contempla la protección del medio ambiente, sino también la subordinación de la conducta del inversionista extranjero a la normatividad ambiental del Estado Anfitrión ( $D A$ v. CR, 2018, párr. 8). Así mismo, el demandado afirmó que las medidas que tomó estaban fundamentadas en las leyes costarricenses ( $D A$ v. $C R, 2018$, párr. 8) y en normas internacionales sobre el medio ambiente que son obligatorias para Costa Rica ( $D A$ v. CR, 2018, párr. 385).

La defensa del demandado pone especial énfasis en el artículo 10.11 DR-CAFTA, según el cual, aquello que se disponga en el capítulo del tratado destinado a la protección de la inversión extranjera no debe interpretarse como un obstáculo para que el Estado Anfitrión tome medidas de protección del medio ambiente ( $D A$ v. CR, 2018, párr. 385).

Además, Costa Rica invoca el artículo 17.1. DR-CAFTA, que reconoce el derecho legítimo del Estado Anfitrión para adoptar políticas y legislación de tipo ambiental; y el 17.2. DR-CAFTA, que reconoce al Estado Anfitrión el ejercicio de la discrecionalidad razonable para regular, fiscalizar y presentar acciones ante los tribunales relacionadas con los recursos ambientales (DA v. CR, 2018, párr. 409).

Cabe resaltar que Costa Rica no solo se limitó a solicitar la declaración de la falta de jurisdicción del Tribunal y la ausencia de responsabilidad, sino que solicitó que se declarara responsable al demandante por los daños ambientales causados por el "Proyecto Las Olas" (DA v. CR, 2018, párr. 185).

El Tribunal encontró serias incongruencias y contradicciones entre los documentos de distintas autoridades nacionales y locales relacionados con permisos y autorizaciones, así como ambigüedades en las declaraciones de estas sobre la existencia de los humedales y la tala de árboles ( $D A v$. CR, 2018, párss. 95-97). 
Por ejemplo, dentro del expediente se pudo verificar, por un lado, la existencia de un concepto favorable al proyecto que era una falsificación supuestamente proveniente de la autoridad nacional de conservación SINAC - que aseguraba la viabilidad ambiental del proyecto ( $D A$ v. $C R$, 2018, párr. 116) y; por otro lado, existían conceptos verídicos de la autoridad técnica nacional ambiental —SETENA — afirmando que la operación del proyecto no se encontraba dentro de un Área Silvestre Protegida (ASP) (DA v. CR, 2018, párr. 114).

También se pudo comprobar que, mientras la municipalidad confirmó la existencia de humedales, tala de árboles y calles pavimentadas sin autorización (DA v. CR, 2018, párr. 123), se mantuvo vigente el Permiso Viabilidad Ambiental (VA) del proyecto, otorgado por la autoridad técnica nacional ambiental —SETENA (DA v. CR, 2018, párss. 161-162)—. Además, se decretaron medidas cautelares de suspensión por parte de un juez penal, el Tribunal Ambiental de Costa Rica - TAA - y la autoridad nacional de conservación —SINAC (DA v. CR, 2018, párr. 165)—.

A pesar de los equívocos que pudiesen surgir de los actos de las autoridades costarricenses, el Tribunal no halló responsable al Estado Anfitrión de compensar daños al inversionista ( $D A$ v. CR, 2018, pág. 263). Esta decisión se fundamentó en la verificación de que en el área del "Proyecto Las Olas" sí existían humedales y bosques protegidos ( $D A$ v. CR, 2018, párss. 506,518 ); en el incumplimiento de la carga que tenía el inversionista para identificar los riesgos ambientales al presentar su solicitud de Viabilidad Ambiental a las autoridades ( $D A$ v. $C R, 2018$, párss. 552-553); en el análisis según el cual, si el inversionista hubiera identificado los riesgos a los humedales y bosques en su solicitud, se habría concedido una viabilidad en otros términos que permitirían desarrollar el proyecto sin dificultades (DA v. CR, 2018, párr. 558); en el argumento de que el demandante no podía pretender excusar su omisión en las supuestas fallas de inspección de las autoridades ambientales costarricenses ( $D A$ v. CR, 2018, párr. 559); en la mala fe del inversionista al fraccionar el área cubierta por la solicitud de Viabilidad Ambiental con el fin de evitar reportar la existencia de humedales y bosques ( $D A v$. CR, 2018, párr. 564), y; en el daño causado a los humedales y bosques ( $D A v$. $C R, 2018$, párss.585-586). 
David Aven y otros v. Costa Rica: reflexiones sobre el interés (global) del medio...

En relación con la demanda de reconvención presentada por Costa Rica, aunque el Tribunal no encuentra en líneas generales razones para no aceptar la jurisdicción, decidió desestimar aquella por el incumplimiento de los requisitos de los artículos 20 y 21 del reglamento de la Comisión de las Naciones Unidas para el Derecho Mercantil Internacional -CNUDMI (DA v. CR, 2018, párss.749)-. Específicamente, no se explicaron con detalle los hechos que fundamentan la reconvención ni la reparación que se pretendía ( $D A$ v. $C R, 2018$, párr.747).

La controversia que origina la Decisión $D A v$. $C R$ pone de presente la tensión que puede surgir entre la necesidad - local y global - de proteger el medio ambiente y la protección otorgada a los inversionistas extranjeros a través de los tratados internacionales de inversión y los capítulos de inversión de los tratados de libre comercio (2). Más aún, las consideraciones del Tribunal sobre la aplicación directa del derecho internacional del medio ambiente a las disputas de arbitraje de inversión, la consagración de la obligación internacional del inversionista de respetar el medio ambiente y la aceptación de jurisdicción de demandas de reconvención por daños al medio ambiente, representan novedades en la práctica del derecho internacional de inversión que cabe destacar (4). La aproximación del Tribunal sobre estos temas, sumado a su predilección por la doctrina de los poderes de policía (3), evidencia un rebalance - que viene reclamando la academia - de los poderes regulatorios del Estado Anfitrión en asuntos ambientales y del interés global del medio ambiente con la protección del inversionista extranjero (5).

\section{La tensión entre el interés (global) del medio ambiente y la protección del inversionista}

El Tribunal plantea de entrada en el encabezado que denomina "El enfoque del Tribunal" la tensión que emana en esta controversia entre el deber del Estado anfitrión de proteger el interés del medio ambiente y el deber de proteger los derechos del inversionista según el tratado:

El Tribunal de Arbitraje se enfrenta a la necesidad de determinar si la protección otorgada en virtud del capítulo 10 del DR-CAFTA 
otorgado a los inversionistas se encuentra subordinada a las leyes promulgadas por las partes del Tratado con el fin de proteger el medio ambiente, y en qué circunstancias puede un Estado que es parte del DR-CAFTA establecer leyes, políticas o adoptar medidas con dicho fin (DA v. CR, 2018, párr. 406)

Este problema jurídico (¿y político?) que señala la Decisión se enmarca dentro de uno de los grandes interrogantes — si no el más importante- que emerge en relación con el derecho de inversión internacional: ¿cómo lograr un balance entre el interés público del Estado y el interés del inversionista?

Uno podría decir que la mayoría de los artículos, tesis y decisiones de arbitraje sobre inversión internacional - de una manera u otra-intentan interpretar los tratados de inversión de forma tal que exista una relación equilibrada entre los poderes regulatorios del Estado Anfitrión y los derechos que surgen a favor del inversionista.

Cabe resaltar, los interrogantes que surgen de la tensión entre los intereses del Estado Anfitrión y del inversionista se agudizan aún más cuando entra en juego otra capa: los intereses globales públicos. Es decir, en una disputa de Arbitraje de Inversión pueden confluir distintos intereses públicos Estatales, intereses públicos globales e intereses del inversionista. Estos se alinean, superponen y enfrentan dependiendo del caso.

Algunas veces, en una disputa de inversión el interés público global se alinea con el interés público del Estado y otras veces se alinea con el interés privado del inversionista. Piénsese por ejemplo que, si bien el interés global del medio ambiente estaría orientado en el mismo sentido que el interés del Estado Anfitrión cuando este toma una medida regulatoria que afecta negativamente al inversionista para evitar daños al ecosistema; el interés del Estado sería contrario al medio ambiente cuando una medida administrativa cancela la operación de inversionistas en energías renovables. En esta última hipótesis, es el interés del inversionista y no el interés del Estado el que está orientado en el mismo sentido del interés público global. Ciertamente, en la mayoría de las disputas de arbitraje de inversión relacionadas con el medio ambiente es el interés del Estado el que se superpone con el interés global y no el del inversionista. 
David Aven y otros v. Costa Rica: reflexiones sobre el interés (global) del medio...

El caso de $D A v$. CR, es uno de aquellos casos donde la disputa gira alrededor de medidas regulatorias de interés público para la protección del medio ambiente que chocan con los intereses del inversionista, pero que están en consonancia con el interés público global del medio ambiente. Específicamente, nos referimos a los actos administrativos y judiciales de suspensión que tenían como finalidad la salvaguarda de los humedales y bosques ubicados en la zona del impacto del "Proyecto Las Olas".

De hecho, se podría afirmar - de acuerdo con las consideraciones del Tribunal- que el afán de Costa Rica por proteger los humedales en este caso está en consonancia con la Convención de Ramsar sobre los Humedales de 1971 (DA v. CR, 2018, párr. 417), el Convenio sobre Biodiversidad de Río de Janeiro de 1992 (DA v. CR, 2018, párr. 418); la Conferencia de las Naciones Unidas sobre el Medio Ambiente y el Desarrollo ( $D A$ v. CR, 2018, párr. 443), la Declaración de Estocolmo de 1972 (DA v. CR, 2018, párr. 445).

Naturalmente, la búsqueda del equilibrio entre el interés del inversionista y el interés (global) público del medio ambiente no se puede resolver de forma matemática, luego las tendencias ideológicas y la lectura del contexto tienen un peso importante al tomar postura en esta disciplina.

Mientras aquel que cree en el discurso neoliberal de la década del noventa y comienzos del nuevo milenio tenderá a favorecer la posición del inversionista, quien siente que la globalización de las inversiones es nociva para el desarrollo económico, social y ecológico de los Estados propenderá por privilegiar los intereses no económicos; y dentro de estos extremos se podrá encontrar posturas intermedias que no ven la paleta en solo dos colores, que tratan de sacudirse de ideologías y leer el contexto junto con las particularidades del caso concreto.

La masificación en los últimos 30 años de los tratados de inversión revela que los Estados y operadores jurídicos confían en la protección al inversionista extranjero como instrumento para el crecimiento de la economía local y global (Manger, 2010, pp. 41-42). La lógica es que los tratados de inversión incentivan las inversiones desde Estados que tienen un superávit de capital hacia Estados que son importadores de capital, mediante un sistema que permite a los inversionistas extranjeros gozar de una protección especial y acudir a árbitros internacionales-neutrales en el evento que sus intereses sean pisoteados por el Estado anfitrión (Thunell, 1977, p. 4). 
Sumado a dicha lógica, la narrativa que redondea los tratados de inversión es adornada con un gana y gana (win-win situation): ganan los Estados Anfitriones al recibir inversión extranjera - que le da dinámica y crecimiento a su economía; gana el Estado de origen de la inversión al momento en que se repatrian las utilidades y gana la comunidad internacional en general por el descubrimiento de nuevos mercados (Price, 2017, pp. 126-127)-.

Ahora bien, así como en el mainstream existe consenso sobre los beneficios para la economía de los tratados de inversión, también existe un consenso sobre una de las externalidades negativas de la protección internacional al inversionista extranjero: la relajación o enfriamiento regulatorio. Este fenómeno se refiere a la parálisis del Estado en la toma de acciones regulatorias para proteger intereses (globales) públicos, al vislumbrar la posibilidad de enfrentar una demanda en arbitraje de inversión internacional por tomar medidas en ese sentido (Schill, 2007, p. 470; Alschner y Tuerk, 2013, p. 222; Bankes, 2012, p. 498).

Las disputas de arbitraje de inversión suponen un riesgo económico significativo para los Estados-Anfitriones, no solo por las pretensiones multimillonarias de los reclamos - que pueden ser una porción relevante del gasto público- sino también por los costos procesales y de representación (Johnson, Sachs, Güven y Coleman, 2018). Se puede identificar distintos niveles de intensidad de la relajación regulatoria, que van desde el riesgo que supone la existencia del derecho de inversión en sí misma (Internalization Chill); pasando por la materialización de ese riesgo en reclamos por parte de los inversionistas (Threat Chill); y llegan hasta las estrategias globales de las empresas multinacionales para sembrar deliberadamente miedo en los Estados Anfitriones al litigio en arbitraje de inversión en contra de aquellas (Transboudary Chill) (Tienhaara, 2018).

Efectivamente, decisiones que favorecen la protección al inversionista enaltecen la racionalidad del sistema de derecho de inversión, i. e. promueven el crecimiento y la fluidez de la economía; del otro lado, decisiones que favorecen elementos contra-racionales pueden servir para mitigar los efectos negativos que el derecho de inversión tiene sobre la capacidad del Estado Anfitrión para proteger intereses (globales) públicos, incluyendo el medio ambiente, i.e. disminuyen la relajación regulatoria. 
David Aven y otros v. Costa Rica: reflexiones sobre el interés (global) del medio...

El reto del Tribunal en $D A v$. CR es, entonces, moverse dentro de las dos variables que representan la tensión entre la protección al inversionista y la autonomía del Estado para regular; el reto es tomar una decisión entre la racionalidad del sistema y la relajación regulatoria. Si optase por reafirmar la racionalidad del sistema mediante la protección al inversionista, el Tribunal estaría incentivando el flujo transnacional de capitales; si le diera relevancia al riesgo de relajación estaría incentivando la protección del interés (global) público que pretende promover el Estado Anfitrión.

En el caso concreto la decisión parece estar orientada a darle mayor valía al interés del medio ambiente - sin decir con ello que la protección de la inversión quede totalmente relegada a un segundo plano-. Muestra de ello es la predilección del Tribunal por la Doctrina de los poderes de policía, así como el reconocimiento que este hace de la obligación a cargo del inversionista de respetar el medio ambiente y de la procedencia de demandas de reconvención por daños al medio ambiente.

\section{La predilección por la doctrina de los poderes de policía}

En relación con el equilibrio de los intereses del inversionista y los intereses (globales) públicos, el Tribunal toma una postura que se podría clasificar dentro de una tendencia que favorece el poder regulatorio del Estado Anfitrión en materia ambiental y el interés global del medio ambiente sobre la protección a la inversión. Ahora bien, la posición del tribunal no tiene la vocación de anular de forma absoluta la protección al inversionista, pues somete las medidas ambientales del Estado a ciertos requisitos para que pueda prosperar como defensa.

De forma explícita la Decisión establece que el mandato del artículo 10.11 DR-CAFTA, consistente en no interpretar las normas que protegen la inversión extranjera como impedimento para que el Estado tome medidas de tipo ambiental, no implica una subordinación absoluta del inversionista a estas medidas ( $D A$ v. CR, 2018, párr. 412). Tampoco —según el Tribunal- implica una subordinación absoluta del inversionista a la regulación ambiental del 17.2. DR-CAFTA, que reconoce la discrecionali-

dad del Estado Anfitrión para regular, fiscalizar y presentar acciones ante 
los tribunales relacionadas con los recursos ambientales (DA v. CR, 2018, párr. 413).

Ahora bien, la Decisión aclara que si bien el artículo 10.11 DR-CAFTA no supone que se puedan ignorar las normas que establecen estándares de protección al inversionista, sí entraña "dar preferencia a los estándares de protección ambiental que fueron declarados de interés para las Partes del tratado al momento de su firma" ( $D A v$. CR, 2018, párr. 412).

Valga anotar, los artículos 10.11 y 17.2 DR-CAFTA no expresan abiertamente que las medidas ambientales justifiquen la vulneración de los intereses del inversionista y tengan como consecuencia la ausencia de responsabilidad.

En lo que respecta al texto del artículo 10.11, si bien este establece que la protección de la inversión no se debe interpretar como impedimento para la protección del medio ambiente, limita la efectividad de este artículo a que las medidas ambientales sean "[...]por lo demás compatible[s]" con las obligaciones a cargo del Estado establecidas en el capítulo sobre inversión (art. 10.11 DR-CAFTA). En este sentido, la ambigüedad del texto podría dar origen a una interpretación contraria a aquella del Tribunal, según la cual en todo caso la acción ambiental del Estado debe estar conforme con los intereses del inversionista.

También el artículo 17.2. podría dar lugar a una interpretación distinta a aquella del Tribunal, pues podría entenderse que su objeto es ratificar la autonomía del Estado Anfitrión para tomar medidas de tipo ambiental y reafirmar la idea de que el debilitamiento de las normas ambientales no debe ser un elemento para atraer la inversión; pero de ninguna forma podría interpretarse que el artículo establece una excepción a la responsabilidad del Estado por acciones de tipo ambiental. De hecho, se podría argumentar en este sentido que la protección al inversionista no envuelve un abandono de la autonomía para regular, sino que sencillamente establece el deber de indemnizar en caso de incumplimiento (débito secundario), luego técnicamente no implica una restricción a su libertad de tomar acción en interés público.

En vista de que pueden existir interpretaciones contrarias a las del Tribunal y que los textos del tratado no son directos en establecer las medidas ambientales como una excepción a la responsabilidad del Estado Anfitrión 
David Aven y otros v. Costa Rica: reflexiones sobre el interés (global) del medio...

por incumplimiento de las obligaciones contenidas en el DR-CAFTA, se puede decir, sin miedo a la equivocación, que el Tribunal tomó una postura - dentro de la discrecionalidad que le corresponde - para favorecer el interés del medio ambiente sobre el interés del inversionista.

Ahora bien, el Tribunal se encarga de aclarar que la preferencia por las medidas ambientales encuentra límites en la justicia, la buena fe, la no discriminación y el debido proceso ( $D A v$. $C R, 2018$, párss. 412-413). Es decir, cualquier medida ambiental del Estado Anfitrión que sea injusta, contraria a la buena fe, discriminatoria y/o violatoria del debido proceso, no será tenida como fundamento para eximirlo de responsabilidad en arbitraje de inversión. En dicho caso, la protección al inversionista prevalecería sobre la protección al medio ambiente.

La preferencia que el Tribunal le da en este caso al medio ambiente parece evocar la doctrina de los poderes de policía. Valga anotar, el Tribunal no afirma esto expresamente pero su razonamiento parece compaginar con dicha doctrina.

Según la doctrina de los poderes de policía, las medidas regulatorias del Estado que son en el interés público no son susceptibles de violar las obligaciones del tratado de inversión. Esta teoría, que tiene su origen en la interpretación del estándar de expropiación (indirecta) - y posteriormente se extiende a otros estándares de los tratados de inversión- ha sido propuesta por varios autores como forma de equilibrar el interés del medio ambiente con el interés del inversionista y medio para disminuir la relajación regulatoria (Baetens, 2010; Schill, 2007; Viñuales, 2015).

La doctrina de los poderes de policía, además, tiene antecedentes en la práctica de los Tribunales de inversión. El caso de Methanex $v$. USA es tal vez el más citado como ejemplo de la doctrina de poderes de policía (Methanex Corporation v. United States of America, 2002). Este caso se refiere a la prohibición de producir éter butílico terciario de metilo en California por riesgos para el medio ambiente, con el resultado de perjudicar a un inversionista canadiense que usaba este insumo para producir metanol. La tesis del Tribunal de Methanex en relación con la prevalencia del interés público del medio ambiente es que no se violaba el estándar de expropiación porque "generalmente en derecho, una regulación no discriminatoria en el interés público $[\ldots]$ no se considera expropiatoria o sujeta a compensación 
[...]" (Methanex Corporation v. United States of America, 2002, Part iv, párr. 7, traducción mía).

Análogamente a lo establecido por el Tribunal en $D A v$. CR, la tesis de Methanex ha sido compartida por algunos Tribunales sujeta a las condiciones que la medida regulatoria sea en interés público, de buena fe y no discriminatoria (Pope \& Talbot Inc. v. The Government of Canada, 2000, párr. 96; S.D. Myers Inc. v. The Government of Canada, 2002, párss. 281-283; Saluka Investments B.V. v. The Czech Republic, 2006, párr. 255).

Valga anotar, hay otras decisiones que adoptan la doctrina de los poderes de policía, limitada por más requisitos a los establecidos por la línea de Methanex. En estas decisiones se ha agregado la necesidad de requerir que la medida del Estado Anfitrión sea proporcional y razonable (Técnicas Medioambientales Tecmed S.A. v. The United States of America, 2003, párr. 122). Esto implica un test más estricto para que la acción ambiental del Estado Anfitrión califique como fundamento suficiente para eximirlo de responsabilidad. También es importante resaltar, que la doctrina de los poderes de policía se opone a la doctrina de los efectos — tesis que ha sido adoptada por algunas decisiones-. Según esta, para la configuración de expropiación indirecta solo se necesita que la medida regulatoria haya destruido el valor de la inversión, ignorando el carácter de interés público de la medida (Metalclad Corporation v. The United Mexican States, 2000, párr. 103; Azurix Corp. v. The Argentine Republic, 2006; Compañía del Desarrollo de Santa Elena S.A. v. Republic of Costa Rica, 2000; Occidental Petroleum Corporation and Occidental Exploration and Production Company v. The Republic of Ecuador, 2012, párss. 443-456; Marion Unglaube v. Republic of Costa Rica, 2012, párss. 205 y 257).

En este orden de ideas, se debe concluir que el Tribunal en $D A v$. CR tomó posición por la postura que - dentro de las posibilidades que surgen de la práctica de los tribunales de inversión- otorga mayor espacio regulatorio al Estado Anfitrión en asuntos ambientales y maximiza la protección del interés global de medio ambiente. 
David Aven y otros v. Costa Rica: reflexiones sobre el interés (global) del medio...

\section{Consideraciones sobre la aplicación del Derecho Internacional del Medio Ambiente}

Para el Tribunal parece no existir duda sobre la relevancia del derecho internacional en la controversia ( $D A v$. $C R, 2018$, párr. 411). No podría ser de otra manera, pues el artículo 10.22.1. DR-CAFTA hace referencia a las "normas aplicables del derecho internacional" como aquellas que gobiernan la disputa ( $D A v$ v. $C R, 2018$, párr. 411). A este respecto cabe diferenciar cuando el Tribunal está interpretando el texto del tratado conforme al contexto del derecho internacional y cuando está aplicando directamente el derecho internacional ambiental como fuente de obligaciones para el inversionista.

La primera aproximación del Tribunal sobre la aplicación del derecho internacional a las disputas de arbitraje de inversión está sustentada en los principios de interpretación de los tratados establecidos en el artículo 31 de la Convención de Viena sobre el Derecho de los Tratados de 1969 (CVDT) (DA v. CR, 2018, párr. 411). De ahí que, el derecho internacional sea concebido por el Tribunal como un instrumento para interpretar dentro de un contexto el sentido estricto de las disposiciones del DR-CAFTA ( $D A v$. $C R, 2018$, párr. 411). En otras palabras, bajo esta perspectiva el Tribunal no busca aplicar directamente normas del marco legal internacional del medio ambiente. Más bien parece atribuirle a este cuerpo normativo una función meramente interpretativa, que asiste al operador jurídico en desentrañar el significado del texto del tratado conforme al contexto del que hace parte.

En consonancia con los lineamientos de la CVDT, la Decisión hace un barrido por distintos instrumentos que integran el marco legal internacional del medio ambiente con el objeto de interpretar el texto DR-CAFTA dentro del contexto del derecho internacional y determinar hasta dónde el marco normativo de Costa Rica se acompasa con este. Destacan dentro de los instrumentos citados por el Tribunal, la Decisión de la Convención de Ramsar sobre los Humedales de 1971 (DA v. CR, 2018, párr. 417); el Convenio sobre Biodiversidad de Rio de Janeiro de 1992 (DA v. CR, 2018, párr. 418); la Conferencia de las Naciones Unidas sobre el Medio Ambiente y el Desarrollo ( $D A$ v. CR, 2018, párr. 443), la Declaración de Estocolmo de 1972 (DA v. CR, 2018, párr. 445). 
En relación con la demanda de Reconvención presentada por el Estado Anfitrión, el Tribunal acoge la tesis del demandado sobre la admisión de la jurisdicción ( $D A$ v. CR, 2018, párr. 728). Tras afirmar que "no cabe duda" que la intención de las partes del tratado - expresada en el artículo 10.28 DR-CAFTA en concordancia con los artículos 10.26.1 y 10.26.28 - es que el demandante solo puede ser el inversionista, el Tribunal asegura que el DR-CAFTA también concibe la reconvención ( $D A$ v. CR, 2018, párr. 732).

Adiciona el Tribunal que, como el DR-CAFTA contempla esencialmente obligaciones para el Estado Anfitrión y, en principio, no concibe obligaciones a cargo del inversionista, valdría la pena preguntarse cuál es la obligación cuyo incumplimiento sustentaría la reconvención. En otras palabras, el Tribunal acepta que pareciera difícil concebir una demanda de reconvención por incumplimiento de obligaciones a cargo del inversionista si no existen estas obligaciones en el texto del tratado ( $D A v$. CR, 2018, párr. 731).

Para resolver el interrogante de cómo fundamentar una demanda de reconvención sin obligaciones explícitas en el tratado a cargo del inversionista, el Tribunal afirma que existen obligaciones implícitas en el DR-CAFTA y, dentro de estas, obligaciones de tipo ambiental. La decisión señala que aquellas obligaciones implícitas derivan de los artículos 10.9.3 y 10.11. (DA v. CR, 2018, párss. 732-733):

Artículo 10.9.3. Requisitos de Desempeño [...] (c). Siempre que dichas medidas [del Estado Anfitrión] no se apliquen de manera arbitraria o injustificada, y siempre que tales medidas no constituyan una restricción encubierta al comercio o inversión internacionales, los párrafos 1(b), (c) y (f), y 2(a) y (b) [sobre los Requisitos de Desempeño que debe cumplir el inversionista] no se interpretarán en el sentido de impedir a una Parte adoptar o mantener medidas, incluidas las de naturaleza ambiental:(i) necesarias para asegurar el cumplimiento de leyes y regulaciones que no sean inconsistentes con este Tratado; (ii) necesarias para proteger la vida o salud humana, animal o vegetal; o (iii) relativas a la preservación de recursos naturales vivos o no vivos agotables. 
David Aven y otros v. Costa Rica: reflexiones sobre el interés (global) del medio...

Artículo 10.11: Inversión y Medioambiente. Nada de lo dispuesto en este Capítulo se interpretará como impedimento para que una Parte adopte, mantenga o haga cumplir cualquier medida, por lo demás compatible con este Capítulo, que considere apropiada para garantizar que las actividades de inversión en su territorio se efectúen tomando en cuenta inquietudes en materia ambiental.

La tesis del Tribunal es que los artículos citados elevan las obligaciones de carácter ambiental establecidas en la legislación de Costa Rica a cargo del inversionista de un nivel local a un nivel internacional ( $D A$ v. $C R, 2018$, párr. 734). Más aún, el Tribunal remata diciendo que el incumplimiento de estas obligaciones constituye una violación internacional que impide al inversionista eximirse de los daños ocasionados al medio ambiente ( $D A v$. CR, 2018, párr. 734).

Sobre el reconocimiento a nivel general de demandas de reconvención por incumplimiento de normas ambientales en el sistema de derecho de inversión, el Tribunal es cauto al advertir que la tendencia general de la práctica de los Tribunales es no permitir la reconvención en las disputas donde no está establecido en el tratado dicha posibilidad ( $D A v$. CR, 2018, párr. 736). No obstante, el Tribunal cita como antecedentes de demandas de reconvención los casos de Burlington v. Ecuador y de Urbaser v. Argentina, haciendo claridad que en el primer caso la aceptación de la jurisdicción deriva del acuerdo expreso de las partes de la disputa y, en el segundo caso, deriva de los establecido en el tratado de inversión entre España y Argentina y el Convenio sobre Arreglos de Diferencias Relativas a Inversiones entre Estados y Nacionales de otros Estados - CIADI—(DA v. CR, 2018, párr. 736).

Al citar a Urbaser como un modelo de aceptación de jurisdicción sobre reconvención, el Tribunal incluye como fuente de dicha aceptación, además del tratado de inversión entre España y Argentina y el CIADI, "el derecho internacional de los derechos humanos y el derecho internacional general, con inclusión de los principios generales del derecho internacional" (DA v. CR, 2018, párr. 737).

En este orden de ideas - sin negar que en el caso concreto las obligaciones ambientales derivan del DR-CAFTA - el Tribunal aprovecha lo dicho en Urbaser para reconocer la existencia de obligaciones ambientales sustentadas por fuera del texto del tratado y su aplicación directa a la 
relación entre las partes como fuente de demandas de reconvención: el Tribunal afirma que las obligaciones medioambientales son del interés de todos los Estados y que tienen el carácter de erga-omnes (DA v. CR, 2018, párr. 738). Esto constituye una innovación sin precedentes en la práctica de los Tribunales de arbitraje de inversión internacional.

Reconocer la obligación de respetar el medio ambiente sustentada directamente en normas de derecho internacional y darle a esta el carácter de erga-omnes, dentro del ámbito del derecho de inversión y a cargo del inversionista, va mucho más allá de la interpretación del texto del tratado de acuerdo con la CVDT.

Es distinto interpretar el texto a partir del contexto de derecho internacional, que aplicar la ley internacional directamente como fuente de una obligación. Lo primero, es una práctica frecuente en el derecho internacional de inversión - tal como sucede con tratar de interpretar la obligación de trato justo y equitativo a cargo del Estado conforme al principio internacional de buena fe o al estándar consuetudinario de trato mínimo internacional- lo segundo, es raramente aceptado en derecho internacional y no tiene precedentes como fundamento de responsabilidad del inversionista.

Ciertamente, dentro de las Decisiones de arbitraje de inversión anteriores al caso en comento, sí existen algunos casos donde se ha reconocido deberes a cargo del inversionista. En especial hago referencia al evento en donde se acude a los principios de derecho internacional de abuso del derecho, el abuso del proceso, la buena fe y, en general, al orden público internacional como fuente que origina el deber del inversionista de no explotar su inversión de forma fraudulenta (Churchill Mining PLC and Planet Mining Pty Ltd v. Republic of Indonesia, 2016, párss. 493-528). Sin embargo, este deber opera más como una carga para el reconocimiento de la protección a la inversión que como una obligación en sentido estricto.

El incumplimiento del deber del inversionista de no cometer fraude en la explotación de su inversión tiene como efecto el fracaso del reclamo por falta de jurisdicción -bajo la lógica que el tratado de inversión no protege inversiones fraudulentas- o el fracaso de la reclamación por el hecho de la víctima o la negligencia concurrente - pues se imputa el daño al fraude del demandante y no a la violación de un estándar del tratado por parte del Estado Anfitrión (Yukos Universal Limited (Isle of Man) v. The Russian Federation, 2014, párss. 
David Aven y otros v. Costa Rica: reflexiones sobre el interés (global) del medio...

$1615,1777)$ - En este orden de ideas, estos deberes no se conciben como un poder del Estado Anfitrión que constriñe al inversionista al cumplimiento de la prestación y cuyo incumplimiento genera responsabilidad.

Las consideraciones sobre la aplicación directa del derecho internacional a las disputas de derecho de inversión en $D A v$. CR se extienden más allá del surgimiento de un deber o una carga para el inversionista. La obligación de no dañar el medio ambiente como erga-omnes, teniendo como fuente el derecho internacional, se concreta en una prestación de no hacer en -sentido técnico-jurídico- que constriñe al inversionista a su cumplimiento y puede dar origen a la responsabilidad de este.

Cabe anotar, resulta dudoso el surgimiento en sentido técnico de una obligación internacional de respetar el medio ambiente a partir del texto del DR-CAFTA pues los artículos citados por el Tribunal para sustentar el surgimiento de la supuesta obligación -10.11 y 10.9.3 - no dicen textualmente que el inversionista esté obligado. La interpretación del Tribunal parece un poco forzada, pues aquello que establecen dichos artículos es que la protección de la inversión del tratado no se debe interpretar en el sentido de impedir que el Estado Anfitrión haga cumplir sus leyes ambientales. En este orden de ideas, estos artículos consagran la autonomía del Estado Anfitrión para regular el medio ambiente y — por mucho- la posibilidad de excluir dichas medidas regulatorias como fuente de responsabilidad para el Estado Anfitrión.

A la interpretación forzada parece añadirse algo de ambigüedad en la decisión. Esto se debe a que, aunque según lo descrito en el párrafo anterior el Tribunal encuentra que los artículos 10.11 y 10.9.3 imponen obligaciones de forma implícita al inversionista, casi al final del texto de la decisión el Tribunal llama la atención sobre el hecho de que esas disposiciones, tal como están redactadas, "no imponen —en sí mismas— ninguna obligación afirmativa a los inversionistas" ( $D A$ v. CR, 2018, párss. 743).

Ahora bien, aquello que sí representa un salto gigantesco y que no necesita recurrir a interpretaciones forzadas del texto, es aceptar que en derecho de inversión pueden existir obligaciones erga-omnes a cargo del inversionista cuyo incumplimiento puede derivar en responsabilidad a través de una demanda de reconvención —o, ¿por qué no?, a través de una demanda independiente sin que sea necesariamente de reconvención-. 
Otra consecuencia, también novedosa, de la imposición de la obligación internacional al inversionista se puede percibir desde el punto de vista del tópico de los sujetos de derecho internacional. La práctica del derecho de inversión ha sido en general reacia a reconocer obligaciones a cargo del inversionista por considerar que este no es en principio un sujeto de derecho internacional. A este respecto, el Tribunal establece de forma tajante que "ya no es posible admitir que las empresas que operan a nivel internacional tienen inmunidad porque no son sujetos de derecho internacional" (DA v. CR, 2018, párr. 738).

Si bien al final de cuentas el Tribunal declara que la demanda de reconvención que presentó Costa Rica no es procedente por defectos en la forma, sus consideraciones sobre el reconocimiento del inversionista como sujeto de derecho internacional y la posibilidad de declarar la responsabilidad del inversionista por incumplimiento de la obligación erga-omnes de respetar el medio ambiente, supone un giro sin precedentes en el derecho de inversión que favorece la posición del Estado Anfitrión, disminuye la relajación regulatoria y protege el interés global del clima. Un rebalance entre los intereses del inversionista, del medio ambiente y del Estado Anfitrión que parece necesario.

\section{Conclusión: la necesidad de rebalancear el interés del medio ambiente con la protección del inversionista}

Los estudios críticos del derecho internacional coinciden en señalar que el derecho de inversión tiene un desbalance genético a favor del inversionista (Miles, 2013). Un reflejo de esto es que los tratados en general solo establecen obligaciones a cargo del Estado Anfitrión y no establecen obligaciones a cargo del inversionista; o que solo pueda ser el inversionista quien convoque un Tribunal de Arbitraje.

Además, la asimetría en el poder negocial entre las partes de los tratados de inversión podría llevar a afirmar que el derecho de inversión reproduce patrones imperialistas de dominación del hemisferio norte sobre el hemisferio sur; de países desarrollados sobre países en vías de desarrollo (Miles, 2013, p. 10). Uno de estos patrones imperialistas es la mercantili- 
David Aven y otros v. Costa Rica: reflexiones sobre el interés (global) del medio...

zación del medio ambiente que favorece a grandes corporaciones (Miles, 2013, pp. 3, 10). En este escenario, el resultado más probable de cualquier disputa de inversión cuando entran en conflicto intereses del inversionista con el interés (global) público del medio ambiente es la primacía de aquel sobre este.

Un sistema de derecho de inversión cuyo centro de gravedad es la protección de la inversión requiere ser rebalanceado con la finalidad de otorgar a los intereses no-económicos - como el medio ambiente- un valor superior o equivalente al dado a los intereses del inversionista. Para ello es necesario que los Tribunales y tratados incorporen elementos contra-racionales que hagan efectiva la protección de los intereses (globales) públicos no económicos. Se ha llegado a decir que el sistema de derecho de inversión requiere desarrollar un "desagrado contra sí mismo" para reflexionar sobre su propia racionalidad e implementar correctivos para remediar dicho desequilibrio genético (Franzki y Horst, 2016, p. 358).

$D A v$. $C R$, no solo asume el reto de reflexionar sobre el desequilibrio entre el interés del inversionista y el interés del medio ambiente, sino que adopta consideraciones que estimulan el rebalance entre estos intereses y disminuyen la relajación regulatoria de los Estados Anfitriones en materia ambiental. Por un lado, el Tribunal interpreta lo referente al incumplimiento de las obligaciones del tratado a cargo del Estado Anfitrión bajo la perspectiva de la doctrina de los poderes de policía. El resultado de esto es la primacía del interés (global) del medio ambiente sobre el interés del inversionista, cuando la medida ha sido tomada de acuerdo con el interés público, de buena fe, sin discriminación y respetando el debido proceso. Por otra parte, el Tribunal concibe el surgimiento de una obligación de respetar el medio ambiente a partir de la aplicación directa del derecho internacional del medio ambiente. Todavía más, el Tribunal califica esta obligación como erga-omnes y afirma que su incumplimiento puede derivar en responsabilidad del inversionista en arbitraje de inversión.

El modelo de equilibrio que plantea $D A v$. CR es exitoso al hallar canales de entrada para el medio ambiente, entendido como un interés público merecedor de una tutela especial dentro de un contexto global de devastación acelerada del ecosistema. Se espera que esta decisión sirva como inspiración a las decisiones de arbitraje de inversión internacional, 
cuya interpretación no puede escapar a la preocupación común de toda la humanidad de preservar el medio ambiente, ni ignorar el marco legal internacional que protege y le da un lugar principal a este interés.

\section{Bibliografía}

Alschner, W. y Tuerk, E. (2013). The Role of International Investment Agreements in Fostering Sustainable Development. En Baetens, F. (ed.), Investment Law within International Law: Integrationist Perspectives (pp. 217-230). Cambridge University Press. Recuperado de https://ssrn. com/abstract $=2295440$

Baetens, F. (2010). Foreign Investment Law and Climate Change: Legal Conflicts Arising from Implementing the Kyoto Protocol Through Private Investment. En Cordonier Segger M., Gehring M.W. y Newcombe, A. (eds.), Sustainable Development in World Investment Law. Kluwer Law International. CISDL. Recuperado de https://ssrn. com/abstract $=2117950$

Bankes, N. (2012). Decarbonising the Economy and International Investment Law. Journal of Eenergy \& Natural Resources, 30(4), 497-510.

Franzki, H. y Horst, J. (2016). On the critical potential of law - and its limits: Double fragmentation of law in Chevron v. Ecuador. En Blome, K., Fischer-Lescano, A., Franzki, H., Markard, N. y Oeter, S. (eds.), Contested Regime Collisions: Norm Fragmentation in World Society (pp. 347-371). Cambridge: Cambridge University Press.

Johnson, L., Sachs, L., Güven, B., y Coleman, J. (2018). Costs and Benefits of Investment Treaties: Practical Considerations for States. Columbia Center on Sustainable Energy. Recuperado de https://ssrn.com/ abstract $=3277965$

Manger, M. S. (2010). Common Standards in a Bilateral Economy: a Political Economy Perspective on International Investment Law. Japanese Yearbook of International Law, 53, 41-95.

Miles, K. (2013). The Origins of International Investment Law: Empire, Environment and the Safeguarding of Capital. Cambridge: Cambridge University Press. 
David Aven y otros v. Costa Rica: reflexiones sobre el interés (global) del medio...

Price, D. (2017). Indonesia's Bold Strategy on Bilateral Investment Treaties: Seeking an Equitable Climate for Investment? Asian Journal of International Law, 7(1), 124-151.

Schill, S. W. (2007). Do Investment Treaties Chill Unilateral State Regulation to Mitigate Climate Change? Journal of International Arbitration. 24(5), 469-477.

Thunell, L. H. (1977). Political risk in International Business: Investment Behaviour of Multinational Corporations (Praeger special studies in international business, finance, and trade). New York: Praeger Publisher.

Tienhaara, K. (2018). Regulatory Chill in a Warming World: The Threat to Climate Policy Posed by Investor-State Dispute Settlement. Transnational Environmental Law, 7(2), 229-250.

Viñuales, J. E. (2015). Foreign Investment and the Environment in International Law. Cambridge: Cambridge University Press.

\section{Anexo jurisprudencia citada}

Azurix Corp. v. The Argentine Republic (2006). ICSID Case No. ARB/01/12, 14.05.2006

Churchill Mining PLC and Planet Mining Pty Ltd v. Republic of Indonesia (2016). ICSID Case No. ARB/12/14 and 12/40.

Compañía del Desarrollo de Santa Elena S.A. v. Republic of Costa Rica (2000), ICSID Case No. ARB/96/1, 08.06.2000

David Aven y Otros v. Costa Rica. (2018). ICSID Case No. UNCT/15/3. Marion Unglaube v. Republic of Costa Rica (2012). ICSID Case No. ARB/08/1, 16.05.2012

Methanex Corporation v. United States of America. (2002). UNCITRAL, 07.08.2002.

Occidental Petroleum Corporation and Occidental Exploration and Production Company v. The Republic of Ecuador (2012). ICSID Case No. ARB/06/11, 5.10. 2012

Pope \& Talbot Inc. v. The Government of Canada. (2000). UNCITRAL, 26.06.2000. 
S.D. Myers Inc. v. The Government of Canada. (2002). UNCITRAL, 21.10.2002.

Saluka Investments B.V. v. The Czech Republic. (2006). UNCITRAL, 17.03.2006.

Técnicas Medioambientales Tecmed S.A. v. The United States of America. (2003). ICSID Case No. ARB (AF)/00/2).

Yukos Universal Limited (Isle of Man) v. The Russian Federation (2014). UNCITRAL, PCA Case No. AA 227, 31.07.2014. 